\title{
A VIDA POR UM FIO: A ESCUTA CLÍNICA ENTRE A URGÊNCIA SUBJETIVA E A URGÊNCIA MÉDICA
}

Sílvia Nogueira Cordeiro

Universidade Estadual de Londrina

Fabiola da Silva Miranda

Universidade Estadual de Londrina
Recebido em: 29/07/2020

$1^{\text {a }}$ revisão em: 22/09/2020

Aceito em: 20/11/2020

\section{RESUMO}

Este artigo tem como objetivo discutir os efeitos da escuta do sofrimento a partir do dispositivo da clínica psicanalítica num relato de um caso atendido em um serviço de saúde hospitalar. A urgência médica faz parte da rotina dos profissionais da saúde, que têm a missão de salvar vidas em um curto espaço de tempo seguindo condutas previamente estabelecidas. A urgência subjetiva é um assunto que diz da prática da clínica psicanalítica, especialmente nas instituições de saúde, onde encontramos sujeitos que, ao passar por um momento de adoecimento, muitas vezes desencadeiam uma experiência de intensa angústia. Nessas situações, trabalhar na dimensão do tempo lógico, conforme proposto por Lacan (1945/1998), é um recurso analítico para tratar do sujeito que está num momento de ruptura com o simbólico. A oferta de uma escuta clínica possibilita uma abertura no tempo para a palavra diante do mal-estar subjetivo despertado pelo encontro do real.

Palavras-chave: psicanálise; ambiente hospitalar; saúde. 


\title{
LIFE BY A THREAD: CLINICAL LISTENING BETWEEN SUBJECTIVE AND MEDICAL URGENCY
}

\begin{abstract}
The objective in this article is discusses the effects of listening to suffering from the perspective of the psychoanalytic clinic in a report of a case attended in a hospital health service. Medical urgency is part of the routine of health professionals, whose mission is to save lives quickly following previously established protocols. The subjective urgency belongs to the practice of the psychoanalytic clinic, especially in health institutions, where we find subjects who, when passing through a moment of illness, often trigger intense anguish. In these situations, working in the dimension of logical time, as proposed by Lacan (1945/1998), is an analytical resource to treat the subject in a moment of rupture with the symbolic. Clinical listening allows an opening in time for the word in the face of the subjective turmoil aroused by the encounter of the real.
\end{abstract}

Keywords: psychoanalysis; hospital environment; health. 


\section{LA VIDA POR UM HILO: ESCUCHA CLÍNICA ENTRE LA URGENCIA SUBJETICA E MÉDICA}

\section{RESUMEN}

Este artículo tiene como objetivo discutir los efectos de la escucha del sufrimiento desde el dispositivo del psicoanálisis em un reporte de caso atendido en un servicio de salud. La urgencia médica es parte de la rutina del os profesionales de la salud cuya misión es salvar vidas siguiendo procedimientos previamente establecidos en un corto periodo de tiempo. La urgencia subjetiva es un tema que concierne a la práctica de la clínica psicoanalítica, especialmente em las instituciones de salud, donde encontramos sujetos que están pasando por un período de enfermedad que a menudo desencadena una experiencia de angustia intensa. En estas situaciones, trabajar em la dimensión del tiempo lógico, según el propuesto por Lacan (1945/1998), es un recurso analítico para tratar do sujeto que se encuentra en un momento de ruptura con lo simbólico. La oferta de una escucha clínica permite una apertura em el tempo, para la palabra antes del malestar subjetivo despertado por el encuentro con el real.

Palabras clave: psicoanálisis; ambiente hospitalario; salud. 


\section{INTRODUÇÃO}

Este artigo apresenta, por meio do relato de um caso atendido em um serviço de saúde hospitalar, os efeitos da escuta do sofrimento, a partir do dispositivo da clínica psicanalítica quando há uma urgência que marca o campo do que é subjetivo. Trata-se de um campo que ultrapassa aquilo que diz respeito ao corpo estritamente biológico. Na urgência subjetiva, nos deparamos com um sujeito que está vivenciando uma situação de perda, seja por morte ou doença. Caracteriza um momento de ruptura que ameaça a continuidade da vida

Conforme aponta Batista (2011), a urgência pode ser elevada ao estatuto de subjetiva quando o posicionamento de quem está no lugar que se propõe ofertar uma escuta, a partir de uma experiência analítica, aposta no sujeito que está em sofrimento psíquico.

A experiência do trabalho com a clínica psicanalítica no hospital nos permite observar que a realidade do adoecimento do corpo pode ser uma via de acesso para se perceber, a partir dele, a existência de uma realidade psíquica que se movimenta para suportar o possível aniquilamento do corpo, causado por uma doença ou acidente, que muitas vezes não é possível evitar. No ambiente hospitalar, a urgência e a emergência fazem parte da rotina dos profissionais de saúde; nestes casos, há necessidade de resolver problemas de um organismo que está em desequilíbrio no seu funcionamento. Todavia, o trabalho da equipe médica para salvar a vida não obstrui a possibilidade de se ofertar uma escuta da urgência e emergência de um sujeito pulsando entre sentidos inconscientes (Moura, 2000), que demanda dizer sobre o sofrimento psíquico contido no adoecimento do corpo orgânico.

Entende-se que a urgência médica é prioritariamente um tipo de atenção ao padecimento do corpo biológico, caracterizado como um processo agudo clínico ou cirúrgico, com risco de evoluir para complicações mais graves ou fatais (GiglioJacquemot, 2005). Portanto, há a necessidade de uma intervenção rápida para restabelecer o funcionamento do organismo e garantir a sobrevivência do paciente.

Já a urgência subjetiva pode ser considerada um assunto intrínseco à prática na clínica psicanalítica, em especial no contexto das instituições de saúde (Calazans $\&$ Bastos, 2008), onde com frequência acolhemos sujeitos que estão passando por momento de padecimento do seu corpo-orgânico e anseiam por muito mais que o alívio para a desestabilização orgânica. $\mathrm{A}$ imprevisibilidade dos acontecimentos vividos no corpo, na maioria das vezes, desencadeia uma experiência de intensa angústia.

Na urgência subjetiva, há uma pressa por um saber que vai além dos cuidados que pode receber no seu corpo-orgânico e que se espera receber do outro 
(semelhante). Esses sujeitos buscam um sentido, um significante que possa esvaziar os sentidos que o colocam na condição de "doente" (Berta, 2015).

Neste tipo de urgência, é importante substituir o olhar voltado para os códigos emitidos pela doença e deslocar a atenção para uma escuta do sujeito do inconsciente e, como propôs Lacan (1964/2008, p. 14), tratar "o real pelo simbólico". Esta é a tarefa do psicólogo que trabalha com a clínica psicanalítica no hospital. É preciso olhar o sofrimento sob outra perspectiva e considerar que todo o sofrimento físico pode produzir um sofrimento psíquico.

A temporalidade nessas duas situações de urgência cursa caminhos diferentes. Enquanto a equipe médica tem pressa para salvar a vida e tratar o mal-estar do organismo em um curto espaço de tempo, buscando seu restabelecimento, a temporalidade do sujeito segue em outra direção. A desestabilização do corpoorganismo provoca muitas vezes um encontro com uma situação traumática, não sendo possível encontrar palavras para nomear aquilo que se apresenta como (in)suportável (Azevedo, 2018; Costa \& Costa-Rosa, 2018).

Trata-se de uma temporalidade que pode ser prolongada indefinidamente, pois o sujeito encontra-se paralisado no momento presente. Há uma interrupção do tempo e do espaço, abrindo lugar para um vazio e o surgimento de afetos como angústia e o desamparo. É como se o sujeito estivesse vivendo "fora de si".

Desde os primeiros escritos, Freud (1926/1996) adverte sobre um estado de urgência que se atrela às necessidades vitais, aquilo que está no mais íntimo do sujeito, mas é também sua extimidade, ou seja, aquilo que lhe é estranho. A urgência subjetiva liga-se ao que é estranho ao sujeito e torna-se o centro da direção do tratamento em psicanálise.

Em cada urgência subjetiva há um traço singular que, na oferta da escuta, pode fazer surgir a questão do sujeito, onde ele se localiza, por meio do afeto de angústia. Operar com a clínica psicanalítica nessas situações é fazer passar o singular de cada urgência pelo plano da fala, para um sujeito que está urgindo por um dizer (Azevedo, 2018; Berta, 2015).

É preciso que se instale um tempo para que o sujeito possa falar e traçar as coordenadas simbólicas, um lugar de fala onde ele poderá se dizer (Belaga, 2007; Sotelo, 2014). Essas situações demandam um tipo de atendimento que não se limita ao corpo orgânico, mas ao sujeito que se encontra em um momento de urgência psíquica promovida por um acontecimento inesperado que o confronta com o sofrimento, a dor e a possibilidade de morrer, deslocando-o do seu "quadro da vida". Trata-se de um momento traumático, mas que pode ser fecundo para o sujeito implicar-se com sua subjetividade.

Conforme aponta Ansermet (2015), o trauma é o encontro com aquilo que escapa à simbolização, o sujeito, num primeiro tempo, mergulha no estarrecimento, 
devido à hiância que se abriu entre o acontecimento e a sua capacidade de compreender.

Lacan (1945/1998), ao utilizar o conceito do tempo lógico, evidencia que a elaboração psíquica de um acontecimento traumático segue a temporalidade lógica, ou seja, a ressignificação não obedece à ordem cronológica, sendo inserida na dimensão simbólica do tempo lógico, no qual o sujeito, por meio de divisões do tempo e de sua articulação, pode alcançar uma conclusão.

Podemos dizer que a urgência subjetiva produz um curto-circuito entre o instante de ver (o acontecimento) e o tempo de compreender (esse acontecimento), o sujeito está no intervalo entre o que não existe e o que está preste a existir.

A partir da experiência clínica com uma equipe multiprofissional composta por psicólogo, nutricionista e farmacêutico, discutiremos os efeitos da escuta do sofrimento, a partir do dispositivo da clínica psicanalítica, ao paciente que passa por um momento traumático e está sem recursos para dar conta da sua existência. Ressaltamos que foram tomados todos os cuidados éticos para manter o sigilo das informações sobre o paciente de forma a preservar sua identidade. Alguns elementos do caso estão presentes no artigo somente para contextualizar o trabalho do psicólogo na equipe multidisciplinar. O objeto de estudo surgiu na supervisão do caso a partir das reflexões ocorridas sobre os efeitos da escuta clínica na condução do tratamento, sendo, portanto, um estudo teórico-clínico. Como tal, este estudo se enquadra no proposto pela Resolução 510/2016 do Conselho Nacional de Saúde ( $\$ 1$, item VII), que indica a não necessidade de tramitarem por um Comitê de Ética em Pesquisa com Seres Humanos os estudos que objetivem o aprofundamento teórico de situações que emergem espontaneamente e contingencialmente na prática profissional. Cabe, contudo, ao pesquisador cuidar para não haver a exposição de dados que possam identificar a pessoa".

\section{UMA EXPERIENCIA DE ESCUTA CLÍNICA EM UMA EQUIPE MULTIDISCIPLINAR}

A vida por um fio elucida o caso de Sofia, nome fictício, uma paciente que foi acompanhada por uma equipe multiprofissional de residentes da Saúde da Mulher em um hospital universitário. A equipe é composta por oito profissionais de quatro áreas: Psicologia, Nutrição, Farmácia e Educação Física. Nesse caso, o principal desafio do psicólogo é construir seu lugar para trabalhar com a clínica psicanalítica e sustentar o desejo singular do paciente, ainda que esse desejo esteja em discordância com o tratamento objetivado pela equipe multidisciplinar. Ou seja, o psicólogo praticante da psicanálise terá que operar de um lugar diferente dos demais profissionais da saúde, pautado pela ética da psicanálise, que privilegia o bem dizer, que aposta no singular de cada um, diferentemente do discurso do médico, que, na instituição de saúde, representa o discurso da ciência, lugar de saber e verdade. O psicólogo praticante da psicanálise trabalhará com o sujeito na 
sua singularidade, com o que representa seu adoecimento, ou seja, aquilo que a medicina tenta excluir e não pode tratar.

Sofia, uma jovem com 28 anos, chegou ao Pronto Socorro com um quadro de pancitopenia, uma doença caracterizada pela diminuição de glóbulos brancos, vermelhos e plaquetas no sangue. Este caso chamou a atenção da equipe, primeiro pela gravidade do estado de saúde da paciente e, segundo, porque as investigações das causas do problema indicavam relação com um procedimento médico, realizado num momento anterior, para tratar uma queimadura de terceiro grau. Durante o tratamento da queimadura, ocorrido na mesma instituição de saúde, realizou-se um procedimento para acesso venoso com um fio guia; entretanto, esse fio guia permaneceu dentro corpo da paciente, alojando-se na veia cava, provocando um quadro infeccioso. O retorno da paciente para o hospital aconteceu um ano depois do procedimento. Feito o diagnóstico da causa da infecção, o tratamento implicava a retirada desse fio. Todavia, o procedimento era de alto risco, com grande chance de a paciente morrer, ou seja, sua vida estava "por um fio".

A equipe médica comunicou Sofia e sua irmã (sua acompanhante) sobre o que estava acontecendo e sobre a gravidade do seu estado; informaram a necessidade de retirar o fio alojado na veia Cava e das chances de ela não sobreviver. Na pressa de restabelecer o funcionamento do corpo-organismo, a equipe decidiu realizar com urgência um procedimento menos invasivo para retirar o fio, antes mesmo de Sofia ter tido tempo para compreender o que estava acontecendo. Além desse procedimento não ter tido sucesso, debilitou ainda mais o corpo de Sofia, que teve que ficar em repouso absoluto, na dependência total de cuidados. A intervenção abrupta no corpo de Sofia e a rapidez com que as decisões foram tomadas pela equipe, sem incluir a paciente, provocaram uma série de sentimentos e reações, como angústia, medo e a resistência de submeter-se a uma nova intervenção.

Como já mencionado, a dimensão do tempo numa situação de emergência como esta é muito importante, pois, por um lado, estão os profissionais que atuam num referencial biologista e essencial à vida que são convocados a atenderem às urgências de forma rápida e eficaz para restabelecer a saúde e salvar a vida do paciente seguindo os rigorosos protocolos médicos. Por outro lado, temos o paciente que se depara com o que é inapreensível, o real do corpo, e a inexistência de palavras que possam tecer pela linguagem uma rede de significantes para dar contorno à situação que está vivenciando (Azevedo, 2018; Berta, 2015; Vieira, 2008). É um momento de ruptura que o desestabiliza e o faz mergulhar na inércia da angústia. Um tempo atordoante no instante de ver se fez presente. Sofia resistia a ser submetida a uma nova intervenção em seu corpo e insistia que queria voltar para sua casa.

Se, do lado da medicina, estava presente uma urgência do corpo-orgânico, do lado da paciente emergia uma urgência que toca o campo subjetivo do sujeito. Mohallem (2003) indica que a especificidade da clínica da urgência subjetiva está 
em questão, o que é impossível de se dizer pela linguagem e em palavras. Para Silva (2003), "a clínica psicanalítica na urgência denuncia a ilusão de completude e de eternidade, afirmando a finitude. O sujeito está diante de um mundo que the aponta muitas impossibilidades e, diante do desamparo e do real da castração, a insegurança e a angústia se multiplicam" (p. 14).

Recordamos que o conceito de angústia proposto por Freud (1926/1996a), como desamparo, pode ser tanto por um desamparo por um perigo real quanto desamparo frente às exigências pulsionais. Entretanto, o desamparo é o ponto nodal da situação que representa perigo e que aparece como uma repetição. Lacan dará outra extensão ao conceito de angústia. Seguindo a esteira freudiana, coloca a angústia correlativa ao instante em que o sujeito se vê confrontado em sua existência (Berta, 2015). É correlata ao momento (temporalidade) em que "o sujeito está suspenso entre um tempo em que ele não sabe mais onde está, em direção a um tempo em que ele será alguma coisa na qual jamais poderá se re-encontrar" (Lacan, 1956-1957/1944 p. 231). Neste sentido podemos dizer que Sofia estava vivendo a angústia e o desamparo de uma ameaça real de morte, desencadeada por algo que lhe era estranho, um corpo-estranho (fio condutor alojado na veia cava) e um corpo que talvez the fosse estranho, aquilo que era estranho de si mesma. A (im)possibilidade da vida de Sofia estava na dependência de um "fio"; ficar com ele em seu corpo implicava no risco de ser reduzida ao fio e se desconectar da vida, ou seja, a morte. Consentir com a intervenção necessária implicaria o risco de se (re)conectar à vida e se implicar com ela. Sofia se viu confrontada na sua existência, não tinha como fugir. Os acontecimentos do corpoorgânico evocavam o campo pulsional, provocando uma desorganização psíquica. Sua insistência em voltar para casa pode ser compreendida, num primeiro momento, como um desejo de recuperar a homeostase da sua vida.

O contratempo com que a equipe se deparou diante da resistência de Sofia fez com que solicitassem que a psicóloga acompanhasse o caso na expectativa de que pudesse convencê-la da importância do tratamento.

A pausa no tratamento médico levou a uma brecha para os atendimentos clínicos. A oferta de uma escuta clínica possibilitou a abertura de um tempo na pressa. Ainda que a paciente não estivesse ali em busca de um tratamento psíquico, a oferta de um espaço de escuta abriu a possibilidade de se criar uma demanda. A psicóloga residente da equipe multidisciplinar, advertida pela Psicanálise, pôde se colocar em um lugar que permitiu à paciente uma experiência de não ser o objeto de seu impasse. Sofia pôde voltar-se para si e procurar um sentido na desordem em que se encontrava.

Nos dias que transcorreram, a psicóloga ofereceu sua escuta. No início, houve silêncio. Diariamente, num período de uma semana, a psicóloga esteve ao lado de Sofia. Aos poucos, começou a dizer sobre seu incômodo de estar "presa" na cama do hospital, do constrangimento de não poder cuidar do próprio corpo e da vontade de voltar para casa. Queria ver os sobrinhos, de quem cuidava e a quem 
era muito apegada; também falou sobre sua mãe, que não podia ir vê-la no hospital. Contou sobre seu esposo, que não a via há meses, pois tinha ido para outro estado trabalhar e não tinha como voltar. Relembrou do acidente em que, para salvar os sobrinhos, acabou colocando sua própria vida em risco, queimando grande parte do seu corpo, motivo da sua primeira internação na qual também tinha vivenciado um momento de instabilidade e ameaça de morte.

Sofia estava novamente desamparada, paralisada no instante de ver, enredada pela atemporalidade das fantasias e medos decorrentes da angústia diante da possibilidade de morrer. Há meses estava vivendo numa temporalidade indefinida, provocada por uma ruptura que colocou sua vida em suspensão, entre uma vida que não seria retomada como antes e um futuro incerto e temido. A direção do tratamento foi no sentido de escutá-la e testemunhar com ela esse ponto limite da existência.

Podemos dizer que o trabalho no ambiente hospitalar se assemelha ao experimento preliminar, conforme proposto por Freud (1913/1996b) em "Sobre o início do tratamento", ou seja, deixar o paciente falar livremente, sendo que a única intervenção é fazê-lo prosseguir no que está dizendo. Quinet (2002), em "As 4+1 condições da análise", indica que o "tratamento de ensaio" em Freud, ou "entrevistas preliminares" em Lacan, é o percurso de algumas sessões, entrevistas, para que o sujeito possa formular uma questão, ou seja, a demanda se formula para o sujeito quando ele tem a percepção de verdades existentes por detrás do seu sintoma, que de alguma forma se conectam com sua história.

No caso de Sofia, podemos dizer que a oferta da escuta clínica foi o "fio condutor" que possibilitou conectá-la a uma escuta de si, ao lugar em que se colocava nos arranjos da vida e nos laços afetivos; seus dizeres na vivência da angústia foram circunscrevendo algo na cadeia significante. Entre os dizeres sobre si, suas queixas e seus silêncios, foi possível ir contornando a realidade do que estava acontecendo com seu corpo, dos cuidados que precisava ter com ele. Pode dizer sobre seu sofrimento e indagar-se sobre o acidente que desencadeou todo o processo que estava vivendo. Abriu-se a possibilidade de um tempo na pressa. Sofia teve um tempo para falar de si e talvez ressignificar os acontecimentos de sua vida.

O trabalho com a clínica psicanalítica permite, a partir da fala, que o sujeito construa um caminho, único e singular, muitas vezes se deparando com os obstáculos, com as pedras do caminho que ele mesmo escolheu. Recordamos Miller (1998, p. 13), ao dizer: "é pelo caminho que a pedra existe, mas é também pela pedra que existe o caminho". Neste sentido, podemos dizer que o adoecimento do corpo é como as "pedras" no caminho, que marcam duramente a vida do sujeito. É com esse material rochoso que o psicólogo se depara no trabalho clínico no ambiente hospitalar.

Diante da urgência subjetiva, muitas vezes, a pedra que encontramos é um obstáculo à fala. Os sujeitos tomados pela angústia nos mostram que os recursos 
simbólicos ou imaginários estão oclusos, dificultando uma saída do caos em que se encontra. O trabalho com a clínica psicanalítica vai na direção de possibilitar o encontro do sujeito com a "pedra" no caminho, com o real, para que ele possa encontrar uma saída singular que the possibilite um novo caminhar (Azevedo, 2018).

Passamos da urgência de um corpo adoecido na sua dimensão física para uma urgência de um sujeito adoecido em suas palavras. Ao dizer sobre si, Sofia possibilitou o surgimento de um sujeito e não de um corpo adoecido. Se a angústia é um sinal frente ao mal estar subjetivo que irrompe o sujeito ao encontro do que Ihe é mais caro e singular, um real impossível de simbolizar, o tempo para a escuta e a possibilidade de se escutar abre uma via para que o tratamento possa ser realizado e aquilo que era resistência tornar-se uma possibilidade de se ressignificar.

Com a pausa no tratamento, houve um reordenamento temporal tanto da paciente quanto da equipe, que precisou trabalhar de forma mais integrada.

Como já mencionado, o caso de Sofia foi tratado por uma equipe multidisciplinar, portanto o trabalho do psicólogo não estava desvencilhado da equipe. O desdobramento do tratamento a partir da clínica psicanalítica, produziu consequências tanto na relação do paciente com a equipe como desta com a psicóloga. Neste caso, a intervenção da psicóloga parece ter possibilitado à equipe perceber outra dimensão do sofrimento de Sofia, não só como um corpo-doente que precisava de uma intervenção urgente, mas como um sujeito que possui um corpo marcado por histórias, que precisava ser ouvido e incluído no tratamento.

Se, para a medicina, a urgência convoca o médico a intervir no corpo em nome da ciência e do saber, marcado pelo tempo cronológico, para a clínica psicanalítica, a urgência está intimamente ligada ao conceito de sujeito e a uma temporalidade específica do sujeito do inconsciente. Esses sujeitos precisam de um tempo que não é regido pelos protocolos da instituição. Ambas as urgências requerem uma intervenção imediata, só que em tempos diferentes (Azevedo, 2018).

No lugar de onde opera a medicina, há uma tendência de reduzir o sentido dos diferentes ditos do sujeito para se adequar àquilo que é passível de ser inscrito no discurso médico (Clavreul, 1983). Temos então uma pluralidade de sentidos que é eliminado para dar lugar à univocidade. Não é raro o médico se apropriar do discurso do sujeito e transformar os significantes da sua fala em signo, ou seja, em sinais orgânicos compreensíveis para a medicina. Na sua atuação, muitas vezes, o médico descarta o que há de particular no discurso do sujeito, para torná-lo legível e, desta forma, conseguir eliminar ou tratar aquilo de que o paciente se queixa. Nessa lógica, não há espaço para a fala do paciente, ele não possui saber que interesse ao campo médico. Trata-se aí de um discurso que exclui a diferença, maneira pela qual a subjetividade poderia se manifestar (Machado \& Chatelard, 2014; Moreto, 2013; Silva, 2017). 
Por outro lado, o trabalho com a clínica psicanalítica parte de um outro lugar, o que interessa é o campo subjetivo. Conforme aponta Machado e Chartelar (2014) neste campo, o discurso não tem uma função silenciadora, mas uma função silenciosa, para que se promova a fala do sujeito, pois esta é a via possível para o tratamento.

A medicina impõe ao médico a necessidade de objetivar o sujeito para poder fazer o diagnóstico e propor o tratamento, se possível sem errar. A partir de Freud, aprendemos a escutar sob atenção flutuante, sem destacar a princípio nenhum elemento do discurso do sujeito, pois aí pode surgir uma verdade sobre seu desejo. Ao contrário da medicina, é no erro, no ato falho, naquilo que escapa que temos o fio condutor para o tratamento. Ao dar voz ao sujeito e extrair sua fala, abrimos a possibilidade para tratar seu mal-estar subjetivo.

O trabalho com a clínica psicanalítica é como o trabalho de um artesão, feito um a um; é para cada paciente, de um jeito único. Há uma eficácia terapêutica diferente da proposta terapêutica médica (Azevedo 2016; Machado \& Chatelard, 2014).

Embora a clínica psicanalítica tenha encontrado no ambiente hospitalar uma possibilidade de atuação e este caso pode ser um exemplo dessa possibilidade, observamos que, muitas vezes, se cria um impasse com a equipe médica que tende a padronizar o sofrimento para poder intervir e curar o corpo no menor tempo possível. Neste caso, só foi possível estabelecer um trabalho a partir da clínica psicanalítica porque houve uma demanda dos outros profissionais da equipe para a psicóloga ao se depararem com a resistência da paciente, dizendo que ela queria fazer uma solicitação de alta a pedido porque não queria outra intervenção no seu corpo.

Observamos que, apesar das tentativas da equipe de enquadrar a paciente no tratamento, reduzindo-a ao diagnóstico e destituindo sua singularidade, Sofia resistiu à ordem médica, ao discurso do mestre, causando um transtorno à condução do tratamento pela equipe. Conforme assinala Clevreul (1983), este discurso orienta e sustenta a posição de mestria que o médico representa, a fim de privilegiar objetividade científica.

Esta situação foi desafiadora para a equipe, pois o saber acumulado de cada profissional não foi suficiente para tratar da urgência de Sofia. Manter tal impasse pode proporcionar uma circulação de hipóteses formuladas pela equipe na tentativa de construir um saber não todo acerca do que poderia estar acontecendo com a paciente, ou seja, no tratamento do corpo precisava ser incluído o sujeito em sua dimensão subjetiva. Foi preciso a psicóloga dizer para a equipe que era preciso incluir Sofia nas discussões sobre seu tratamento, pois obedecer às regras diante da doença não é a mesma coisa que ter um sujeito implicado em seu tratamento. 
O impasse que surgiu na condução do tratamento deste caso possibilitou trazer a discussão, entre residentes e tutores, sobre a relevância de introduzir um outro plano de compreensão do sofrimento e da doença, levando em consideração as nuances do psiquismo e da subjetividade. O corpo é o ponto de encontro dos saberes das diferentes áreas; entretanto, há um caminho a se percorrer em busca de estratégias de tratamento que levem em conta a singularidade de cada caso. Com isso não estamos depreciando a importância das práticas de salvamento de vidas sob a ótica da biologia, muito pelo contrário. Compreendemos que, do lugar do qual estes profissionais propõem o tratamento, há uma pertinência. Entretanto, estamos de acordo com o que propõe Lacan (1998): é necessário instituir uma escuta não combativa às intenções da equipe que inclua a oferta de uma ação entre várias, para que se possa contemplar o sujeito do inconsciente e os possíveis direcionamentos de seu tratamento.

\section{CONSIDERAÇÕES FINAIS}

A dimensão da urgência no hospital está presente naquilo que urge do corpo biológico, que, no desequilíbrio do seu funcionamento orgânico, convoca o sujeito a partir do encontro com o real. A possibilidade de ruptura com sua existência o coloca num estado de angústia e desamparo que provoca a ruptura da cadeia simbólica, deixando-o desorganizado no tempo, instituindo do lado do sujeito uma urgência subjetiva. Tomado pelo desamparo e a angústia, muitas vezes, o sujeito não encontra palavras que possam dar um contorno a sua existência, deixando-o à deriva de si mesmo.

Tanto a urgência médica quanto a urgência subjetiva demandam uma conduta dentro de uma temporalidade que, no caso da urgência médica, é regida pelo tempo cronológico, que necessita de uma assistência rápida em um curto espaço de tempo, enquanto que, na urgência subjetiva, estamos diante da temporalidade do inconsciente. Esta urgência ultrapassa o campo da medicina, mas que, quando não é incluída na clínica da urgência no hospital, pode impactar o tratamento médico. A temporalidade que interessa à clínica psicanalítica no ambiente hospitalar está ligada ao tempo lógico, conforme proposto por Lacan (1945/1998) Tempo que possibilita trabalhar a partir da elaboração psíquica diante de um acontecimento traumático, precipitado pela urgência da experiência de desamparo e angústia.

O caso de Sofia pode exemplificar como a urgência do corpo adoecido e a proximidade da morte deixa o sujeito paralisado no instante de ver, naquilo que é impossível de suportar, sem tempo para que ele possa articular uma compreensão e estabelecer uma conclusão (decisão). Foi preciso um tempo na pressa, para que a paciente pudesse, na sua condição de sujeito, ter uma abertura para a palavra. $\mathrm{O}$ trabalho estabelecido a partir da clínica psicanalítica possibilitou dar voz à paciente como forma de reinstalar sua cadeia significante e se reorientar diante do (in)suportável que se apresentava. 
A necessidade da equipe de dar continuidade ao tratamento possibilitou a atuação da psicóloga a partir de outro lugar, não alinhada com o discurso do saber e curar, mas apostando na singularidade do caso, possibilitando à paciente um tempo para construir uma compreensão possível diante do real e da angústia que a colocava numa condição de urgência subjetiva. Nos encontros que aconteceram com a psicóloga, a oferta da escuta abriu a possibilidade de instalar um tempo subjetivo e passar de um impossível de dizer a um bem dizer.

\section{REFERÊNCIAS}

Ansermet, F. (2015). O traumatismo anterior ao nascimento. Opção Lacaniana Online, 16(6), 1-8.

Azevedo, E. (2018). Da pressa a urgência do sujeito: Psicanálise e urgência subjetiva. Analytica, 7(13). Batista, G. (2011). "Fora do protocolo": Intervenção psicanalítica em situação de urgência. In G. Batista, M. D. Moura, \& S.B. Carvalho (Orgs.), Psicanálise e hospital: A responsabilidade da psicanálise diante da ciência médica, (Vol. 5, pp. 133-142). Rio de Janeiro: Wark.

Berta, S. L. (2015). Localização da urgência subjetiva em psicanálise. A Peste, 7(1), 95-105.

Belaga, G. (2007). Presentación. In G. Belaga (Org.). La urgencia generalizada: la práctica en el hospital (pp. 09-30). Buenos Aires: Grama.

Calazans, R., \& Bastos, A. (2008). Urgência subjetiva e clínica psicanalítica. Revista Latinoamericana de Psicopatologia Fundamental, 11(4), 640-652. https://dx.doi.org/10.1590/S141547142008000400010

Clavreul, J. (1983). A ordem médica: Poder e impotência do discurso médico. São Paulo: Brasiliense.

Cordeiro, S. N., Corsino, D. L., \& Barbosa, G. K. (2019). A clínica psicanalítica e os impasses para a atuação na equipe multidisciplinar. Simpósio de Psicanálise e Prática Multidisciplinar na Saúde, (1), 50-58.

Costa, M. F., \& Costa-Rosa, A. (2018). O dispositivo clínico da urgência na atenção hospitalar: Sofrimento, escuta e sujeito. Revista Subjetividades, 18(2), 45-58.

Freud. S. (1996) Inibição, sintoma e angústia. In S. Freud, Edição Standard Brasileira das Obras Psicológicas Completas de Sigmund Freud (Vol. XX, p.81-1974). Rio de Janeiro: Imago. (Originalmente publicado em 1926).

Freud. S. (1996). Sobre o início do tratamento (novas recomendações sobre a técnica da psicanálise I). In S. Freud, Edição Standard Brasileira das Obras Psicológicas Completas de Sigmund Freud (Vol. XII, p.137-160). Rio de Janeiro: Imago. (Originalmente publicado em 1913).

Giglio-Jacquemot, A. (2005). Definições de urgência e emergência: critérios e limitações. In: Urgências e emergências em saúde: perspectivas de profissionais e usuários [online] (Antropologia e Saúde collection, pp. 15-26). Rio de Janeiro: FIOCRUZ.

Lacan, J. (1998). O tempo lógico e a asserção da certeza antecipada. In Escritos (pp.197-213). Rio de Janeiro: Jorge Zahar. (Original publicado em 1945).

Lacan, J. (2008). O Seminário, livro 4. A relação com o objeto. Rio de Janeiro: Zahar. (Originalmente publicado em 1964).

Machado, M. D. V., \& Chatelard, D. (2014). O lugar do psicanalista nos hospitais gerais: entre os dispositivos clínicos e os institucionais. Revista Subjetividades, 14(2), 187-202.

Miller, J. A. (1998). O osso de uma análise [Seminário proferido no VIII Encontro Brasileiro do Campo Freudiano e II Congresso da Escola Brasileira de Psicanálise]. Bahia: Biblioteca Agente.

Mohallem, L. N. (2003). Psicanálise e hospital: Um espaço de criação. In. M. D. Moura (Org.). Psicanálise e hospital 3 - tempo e morte: Da urgência ao ato analítico (pp. 23-34). Rio de Janeiro: Revinter.

Moretto, M. L. T. (2013). O que pode um analista no hospital. São Paulo: Casa do Psicólogo.

Moura, M. D. (2000). Psicanálise e urgência subjetiva. In (Org.), Psicanálise e hospital (2a ed., pp. 3 16). Rio de Janeiro: Revinter.

Quinet, A. (2002). As 4+1 condições da análise (12a ed.). Rio de Janeiro: Zahar.

Silva, D. D. (2003). A apropriação imaginária do tempo na práxis da urgência. In M. D. Moura (Org.) Psicanálise e hospital 3 - tempo e morte: Da urgência ao ato analítico (pp. 9-16). Rio de Janeiro: Revinter.

Silva, A. B. H. C (2017). O discurso do analista como possibilidade da psicanálise aplicada no hospital Revista da SBPH, 20(2), 166-187. Recuperado em 19 de julho de 2020 de 
http://pepsic.bvsalud.org/scielo.php?script=sci_arttext\&pid=S1516$08582017000200011 \&$ lng =pt\&tlng=pt.

Sotelo, I. (2014). Que hace un psicoanalista en la urgencia?. In: Perspectivas de la clínica de la urgência (pp. 23-30). Argentina: Buenos Aires: Grama.

Vieira, M. A. (2008). O trauma subjetivo. Psico, 39(4), 509-513.

\section{CONFLITOS DE INTERESSES}

Não há conflitos de interesses.

\section{SOBRE OS AUTORES}

Sílvia Nogueira Cordeiro é docente do Departamento de Psicologia e Psicanálise e do Programa de Pós Graduação em Psicologia da Universidade Estadual de Londrina, Psicanalista, Membro do GT Psicanálise e Clínica Ampliada - ANPEPP.

E-mail: silvianc@uel.br

(iD https://orcid.org/0000-0003-0834-8610

Fabiola da Silva Miranda é psicóloga formada pela Universidade Estadual de Londrina, Especialista em Saúde da Mulher pelo Programa de Residência Multiprofissional em Saúde da Mulher pela Universidade Estadual de Londrina.

E-mail: mirandafabiola94@gmail.com

(iD https://orcid.org/0000-0002-2613-298X 